\title{
EFICIÊNCIA DOS DIALELOS CIRCULANTES NA ESCOLHA DE GENITORES ${ }^{1}$
}

\author{
RUBEN DELLY VEIGA², DANIEL FURTADO FERREIRA e MAGNO ANTÔNIO PATTO RAMALHO ${ }^{4}$
}

\begin{abstract}
RESUMO - O objetivo foi avaliar, por simulação de dados, a eficiência de dialelos circulantes em relação aos completos, nas estimativas de capacidade geral de combinação (CGC) e capacidade específica de combinação (CEC). Foram simuladas 50 linhagens com 100 genes com distribuição independente, efeitos iguais, sem epistasia. Consideraram-se herdabilidades de $10 \%, 20 \%, 50 \%$ e $75 \%$, em modelos com interação alélica aditiva e dominância completa. Utilizaram-se também dados de experimentos disponíveis na literatura, ambos comparados por meio de: correlação entre estimativas de CGC e CEC, e proporções de estimativas nos circulantes que ocorreram nos intervalos de confiança dos completos. Os resultados permitiram concluir que os dialelos circulantes são tão eficientes quanto os completos, tanto na classificação dos pais quanto à $\mathrm{CGC}$ e à $\mathrm{CEC}$, como na magnitude desses parâmetros, e que o número de cruzamentos (s) afeta as estimativas de CGC e de CEC, embora com um valor pequeno de s seja possível obter boa concordância com as estimativas obtidas nos dialelos completos; com baixa herdabilidade, é vantajoso aumentar o número de cruzamentos de cada pai, embora com a metade do número de pais envolvidos já se consiga alta eficiência dos dialelos circulantes.
\end{abstract}

Termos para indexação: métodos de melhoramento, prova de progênie, cruzamento dialélico, capacidade de combinação, simulação, genética quantitativa.

\section{EFFICIENCY OF CIRCULANT DIALLELS IN PARENTAL CHOICE}

\begin{abstract}
This paper aimed to evaluate the efficiency of circulant diallel in relation to the complete ones, with data simulation based on estimates of general combining ability (GCA) and specific combining ability (SCA). Fifty lines with 100 independent genes of same effects and without epistasy were simulated. Heritabilities of $10 \%, 20 \%, 50 \%$ and $75 \%$ were considered, in models with addictive and complete dominant allelic interaction. Real data experiments presented in literature were used. They were compared by means of correlation between estimates of GCA and SCA, and also by means of proportions of estimates in the circulant that occurred in the confidence intervals of the complete ones. It was concluded that the efficiency is the same in both diallels, considering the parents classification in relation to GCA and SCA, and the magnitude of those parameters; that the number of crossings (s) affects the estimates of GCA and SCA, although with a small value of $\mathrm{s}$ it is possible to obtain good agreement with the estimates of the complete diallel; and, that with low heritability it is advantageous to increase the number of each parent crossings, although with the half of the number of parents involved, high efficiency of the circulant diallels is reached.
\end{abstract}

Index terms: breeding methods, progeny testing, diallel crossing, combining ability, simulation, quantitative genetics.

${ }^{1}$ Aceito para publicação em 16 de julho de 1999.

Extraído da tese de doutorado do primeiro autor apresentada à Universidade Federal de Lavras (UFLA), Lavras, MG.

${ }^{2}$ Eng. Agrôn., Dr., Prof. Titular, Dep. de Ciências Exatas, UFLA, Caixa Postal 37, CEP 37200-000 Lavras, MG E-mail: delly@ufla.br

${ }^{3}$ Eng. Agrôn., Dr., Prof. Adjunto, Dep. de Ciências Exatas, UFLA. Bolsista do CNPq. E-mail: danielff@ufla.br

${ }^{4}$ Eng. Agrôn., Dr., Prof. Titular, Dep. de Biologia, UFLA. Bolsista do CNPq. E-mail: magnoapr@ufla.br

\section{INTRODUÇ̃̃O}

Nas espécies vegetais existe, em geral, uma quantidade inumerável de linhagens e cultivares que podem participar dos programas de hibridação para a obtenção das populações segregantes, fazendo-se necessária a utilização de critérios de escolha. A identificação de metodologias eficientes para essa escolha tem recebido grande atenção dos pesquisadores 
(Baenziger \& Peterson, 1991; Abreu, 1997; Souza, 1997; Charcosset et al., 1998).

Entre as metodologias disponíveis, os cruzamentos dialélicos são os mais amplamente utilizados em quase todas as espécies cultivadas. Uma das vantagens dessa metodologia é que ela não só contribui para o processo decisório de escolha de pais e populações segregantes, mas também pode fornecer informações sobre o controle genético dos caracteres.

A principal restrição aos cruzamentos dialélicos é que, com grande número de pais, o número de combinações híbridas a serem obtidas e avaliadas tornase proibitivo. Uma opção que pode dar maior flexibilidade aos cruzamentos dialélicos, com relação ao número de pais envolvidos, são os dialelos circulantes. Esse tipo de dialelo, embora tenha sido proposto há algumas décadas (Kempthorne \& Curnow, 1961) e possibilite o envolvimento de um número muito superior de pais, tem sido pouco utilizado. Isso ocorre porque os melhoristas não têm informações sobre a sua eficiência em relação aos dialelos completos.

Este trabalho teve como objetivo avaliar a eficiência de dialelos circulantes em relação ao dialelo completo, quanto às estimativas da capacidade geral de combinação (CGC) e da capacidade específica de combinação (CEC).

\section{MATERIAL E MÉTODOS}

O trabalho foi realizado em duas etapas: na primeira, foram simulados dialelos com 50 pais, e na segunda, foram utilizados dados disponíveis na literatura.

Inicialmente, considerou-se um dialelo completo com 50 pais. Para isso, foram simuladas 50 linhagens contendo 100 genes, de efeitos iguais e distribuição independente. $\mathrm{Na}$ simulação consideraram-se dois tipos de interação alélica, aditiva e de dominância completa, desconsiderandose a ocorrência de interações epistáticas. Sendo assim, o valor genotípico atribuído a cada linhagem foi obtido pelo somatório dos efeitos genéticos de cada loco. Os valores genotípicos das combinações híbridas envolvendo duas linhagens foram obtidos de modo semelhante ao relatado para as linhagens genitoras.

$\mathrm{Na}$ constituição genotípica das linhagens, procurou-se aleatorizar a distribuição dos locos, de modo que fossem obtidas linhagens com, no mínimo, dois locos com alelos favoráveis, até o total de 100. Desse modo, obteve-se uma população de linhagens com uma ampla variabilidade genética

O valores fenotípicos das linhagens e dos híbridos da geração $\mathrm{F}_{1}$ foram estabelecidos atribuindo-se erros aleatórios aos valores genotípicos. Esses erros foram atribuídos conforme diferentes herdabilidades, no sentido amplo, para a seleção entre pais e híbridos $\left(\mathrm{h}^{2}\right)$, isto é, $10 \%, 20 \%, 50 \%$ e $75 \%$, obtida pela expressão:

$\mathrm{h}^{2}=\sigma_{\mathrm{G}}^{2} /\left(\sigma_{\mathrm{G}}^{2}+\frac{\sigma_{\varepsilon}^{2}}{\mathrm{r}}\right)$,

em que

$\sigma_{\mathrm{G}}^{2}$ é a variância genética obtida a partir dos efeitos genéticos das linhagens e híbridos;

r é o número de repetições em que o dialelo seria avaliado experimentalmente; no caso, $\mathrm{r}=2$;

$\sigma_{\varepsilon}^{2}$ é a variância do erro; no presente contexto, como a $\mathrm{h}^{2}$ foi prefixada e a variância genética é conhecida, obteve-se $\sigma_{\varepsilon}^{2}$ pela expressão:

$\sigma_{\varepsilon}^{2}=\left(\frac{1-h^{2}}{h^{2}}\right) \cdot r \cdot \sigma_{G}^{2}$.

Definindo-se a variância residual e considerando-se que os erros apresentam distribuição normal, com média zero, os efeitos dos erros foram gerados pela função RANNOR do sistema SAS (SAS Institute, 1995).

Uma vez obtidos os valores fenotípicos das linhagens e dos híbridos nas repetições, efetuou-se a análise de variância, e a partir dos resultados médios procedeuse à análise dialélica, adotando-se o procedimento de Griffing (1956), método II, modelo I, apresentado a seguir:

$\mathrm{y}_{\mathrm{ij}}=\mathrm{m}+\mathrm{g}_{\mathrm{i}}+\mathrm{g}_{\mathrm{j}}+\mathrm{s}_{\mathrm{ij}}+\overline{\mathrm{e}}_{\mathrm{ij}}$, em que:

$\mathrm{y}_{\mathrm{ij}}$ é o valor médio da combinação híbrida (iłj) ou do genitor $(\mathrm{i}=\mathrm{j}) ; \mathrm{i}, \mathrm{j}=1,2, \ldots, \mathrm{p}$ (número de genitores); $\mathrm{m}$ é a média geral; $\mathrm{g}_{\mathrm{i}}, \mathrm{g}_{\mathrm{j}}$ são os efeitos da capacidade geral de combinação do i-ésimo e j-ésimo genitores; $\mathrm{s}_{\mathrm{ij}}$ são os efeitos da capacidade específica de combinação entre o i-ésimo e j-ésimo genitores; $\overline{\mathrm{e}}_{\mathrm{ij}}$ é o erro experimental médio.

A partir da análise de variância foi estimada a herdabilidade no sentido amplo para a seleção entre tratamentos avaliados, visando compará-la com o valor paramétrico.

O intervalo de confiança de $\mathrm{h}^{2}$ foi obtido pela expressão de Knapp et al. (1985), e as análises foram feitas utilizando-se o método dos quadrados mínimos, conforme apresentado por Cruz \& Regazzi (1994).

Para cada um dos dialelos completos referenciados anteriormente foram simulados todos os dialelos circulantes 
possíveis, isto é, o número de cruzamentos em que cada pai está envolvido (s). Na presente situação, como o número de pais é par (50), o valor de s foi sempre ímpar, variando de 3 a 49 (Kempthorne \& Curnow, 1961)

Para os oito dialelos completos já mencionados, foram simulados 50 dialelos circulantes, para cada valor de s, e, na obtenção das 50 simulações de cada situação, os pais foram aleatorizados, utilizando-se a função RANUNI (SAS Institute, 1995); os programas desenvolvidos encontramse em Veiga (1998). Cada um deles foi gerado mediante os procedimentos descritos por Kempthorne \& Curnow (1961). Utilizando as médias dos pais e dos correspondentes híbridos obtidos, foi realizada a análise dialélica, pelo método dos quadrados mínimos, conforme procedimento apresentado por Cruz \& Regazzi (1994). Os programas desenvolvidos para obtenção de estimativas dos parâmetros do dialelo, simulação dos dialelos circulantes, bem como as demais análises, foram elaborados com os recursos do sistema SAS, nos módulos de matrizes e de programação (SAS Institute, 1995).

A eficiência dos circulantes em relação ao dialelo completo foi medida segundo os critérios descritos a seguir

A partir das estimativas da CGC de ambos os dialelos, foi estimada a correlação classificatória de Spearman (rc) (Snedecor \& Cochran, 1982). Como foram simulados 50 dialelos circulantes para cada situação, quanto aos valores de $\mathrm{s}, \mathrm{h}^{2} \mathrm{e}$ interação alélica, foi possível identificar os valores mínimo, médio e máximo para cada situação

De modo análogo, foram estimados os valores mínimo, médio e máximo da correlação classificatória de Spearman entre estimativas de CEC no dialelo completo e no dialelo circulante. Como no dialelo circulante há apenas uma fração das combinações híbridas do dialelo completo, evidentemente as estimativas das correlações classificatórias foram obtidas a partir das combinações híbridas comuns.

Com as análises dos dialelos completos, foram obtidas as estimativas da capacidade geral de combinação para cada pai $\left(\hat{\mathrm{g}}_{\mathrm{i}}\right)$, sendo o intervalo de confiança (IC) obtido pela expressão:

$\hat{\mathrm{g}}_{\mathrm{i}} \pm \mathrm{t}_{\alpha / 2} \mathrm{~s}\left(\hat{\mathrm{g}}_{\mathrm{i}}\right)$, em que:

$\hat{\mathrm{g}}_{\mathrm{i}}$ é a estimativa de CGC do pai; $\mathrm{t}_{\alpha / 2}$ é o quantil superior da distribuição $t$ de Student para graus de liberdade do resíduo, cuja $\operatorname{Prob}\left(\mathrm{t}>\mathrm{t}_{\alpha / 2}\right)=\alpha / 2 ; \mathrm{s}\left(\hat{\mathrm{g}}_{\mathrm{i}}\right)$ é o erro padrão da estimativa dado por:

$\mathrm{s}\left(\hat{\mathrm{g}}_{\mathrm{i}}\right)=\sqrt{\frac{(\mathrm{p}-1) \cdot \mathrm{QMerro}}{\mathrm{p}(\mathrm{p}+2) \cdot \mathrm{r}}}$, em que:

QMerro: quadrado médio do resíduo ou erro da análise de variância; $p$ é o número total de pais.
Como para cada uma das situações foram realizadas 50 simulações do dialelo circulante, foi possível estimar a proporção de casos em que a estimativa de $g_{i}$ pertencia ao intervalo de confiança do respectivo pai no dialelo completo. A partir da informação de cada pai foi obtida a proporção média de coincidência.

A partir da análise do dialelo completo foram obtidas as estimativas da capacidade específica de combinação relativa a cada pai ou híbrido $\left(\hat{\mathrm{S}}_{\mathrm{ij}}\right)$, e o IC foi obtido pela expressão:

$\hat{\mathrm{s}}_{\mathrm{ij}} \pm \mathrm{t}_{\alpha / 2} \mathrm{~s}\left(\hat{\mathrm{s}}_{\mathrm{ij}}\right)$, em que:

$\hat{\mathrm{S}}_{\mathrm{ij}}$ é a estimativa de CEC do cruzamento entre os genitores i e j; $s\left(\hat{\mathrm{S}}_{\mathrm{ij}}\right)$ é o erro padrão da estimativa, dado por:

$$
\begin{aligned}
& s\left(\hat{s}_{i j}\right)=\sqrt{\frac{p(p-1) \cdot \text { QMerro }}{(p+1) \cdot(p+2) \cdot r}}, \text { se } i=j ; \\
& s\left(\hat{s}_{i j}\right)=\sqrt{\frac{\left(p^{2}+p+2\right) \cdot Q M e r r o}{(p+1) \cdot(p+2) \cdot r}}, \text { se } i \neq j .
\end{aligned}
$$

Também no caso da CEC, para cada uma das situações, foram realizadas 50 simulações do dialelo circulante, possibilitando estimar a proporção de casos em que a estimativa de $\mathrm{s}_{\mathrm{ij}}$ pertencia ao intervalo de confiança do respectivo pai ou híbrido no dialelo completo. A partir desta informação foi obtida a proporção média de coincidência.

Foram utilizados os dados médios dos pais e dos respectivos híbridos de dois dialelos com a cultura do milho. O primeiro, cujos resultados de produção de espigas ( $\mathrm{t} / \mathrm{ha}$ ) foram publicados por Ferreira (1993), envolveu 28 variedades de milho, e o segundo, publicado por Naspolini Filho et al. (1981), em que foram apresentadas as produtividades médias de produção de espigas ( $\mathrm{t} / \mathrm{ha}$ ) de 18 populações de polinização aberta.

A partir dos dados médios da produção de espigas ( $\mathrm{t} / \mathrm{ha}$ ), e do quadrado médio do erro, foi efetuada a análise dialélica segundo o modelo de Griffing (1956), método II, cujos procedimentos foram semelhantes aos descritos anteriormente. Simularam-se dialelos circulantes, variando o número de cruzamentos por genitores de três a 27 no caso do experimento de Ferreira (1993) e de três a 17 no experimento de Naspolini Filho et al. (1981). Em todos os casos, novamente 50 simulações foram consideradas.

\section{RESULTADOS E DISCUSSÃO}

\section{Dialelos simulados}

Quando se realiza um dialelo, uma das preocupações é classificar os pais com relação à sua capacidade geral de combinação (CGC). Assim, pode-se 
inferir sobre a eficiência dos dialelos circulantes, em relação aos dialelos completos, a partir da classificação obtida dos pais, com relação à CGC, nas duas situações. Na Fig. 1 são apresentadas as estimativas das correlações classificatórias de Spearman, considerando diferentes valores de $h^{2}$ e $s$, na presença e ausência de dominância, respectivamente. Chama a atenção, inicialmente, o fato de que, com $\mathrm{h}^{2}$ acima de $50 \%$, as correlações obtidas são superiores a 0,9 , mesmo com o menor valor de s utilizado, independentemente da interação alélica. Infere-se, então, que para caracteres de alta $\mathrm{h}^{2}$, os dialelos circulantes fornecem praticamente a mesma classificação dos dialelos completos quanto à capacidade de combinação dos pais envolvidos.

Esse resultado é muito expressivo, pois pode reduzir acentuadamente o trabalho dos melhoristas e, sobretudo, possibilitar que se explore com maior intensidade o grande número de genitores disponíveis. No exemplo considerado, essa vantagem fica bem evidente. Para envolver todas as 50 linhagens no dialelo completo, deveriam ser obtidas $1.225 \mathrm{com}-$ binações híbridas, e além disso elas deveriam ser testadas em ensaios com número razoável de repetições, como já comentado. Já no dialelo circulante com $\mathrm{s}=3$, seria necessário obter e testar apenas 75 combinações híbridas, o que é muito mais factível. $\mathrm{Na}$ simulação, constatou-se que quando $\mathrm{h}^{2}$ é baixa, a classificação dos pais com relação à CGC variou de forma mais acentuada com o valor de $\mathrm{s}$. Porém, mesmo com s igual a $3, \mathrm{~h}^{2}$ igual a $10 \%$ e na presença de dominância, o coeficiente de correlação de Spearman médio foi superior a 0,5 . Com s igual a 11 esse valor já ultrapassa 0,7 , e com s igual a 25 , metade do número de pais, já atinge novamente o valor de 0,9 . Esses resultados permitem inferir que os dialelos circulantes possibilitam classificar adequadamente os pais com relação à CGC, mesmo quando o caráter considerado tem baixa herdabilidade. Nesse caso, para maior segurança, pode-se realizar o dialelo circulante com maior número de cruzamentos por pai (s maior).

Mesmo com essa última recomendação de aumentar o valor de s, buscando maior segurança, é necessário enfatizar que esse valor não necessita ultrapassar $50 \%$ do número de pais, até certo ponto contrariando as conclusões de Murty \& Anand (1966) e Murty et al. (1967), que concluíram que os dialelos parciais e os circulantes são recomendados para números de cruzamentos a partir da metade do número de pais. Mesmo nesse caso extremo de $50 \%$, as vantagens do dialelo circulante são marcantes. Com p igual a 50 e s igual a 25, seriam necessários 625 cruzamentos, ao invés dos 1.225 já comentados.

Alguns melhoristas, além da classificação dos genitores com relação à CGC, podem estar interessados nas próprias estimativas das capacidades de combinação, sobretudo por permitirem verificar qual o grau de discernimento entre os genitores, inclusive por meio de testes estatísticos apropriados. Esse poderia ser um outro argumento contra a utilização do dialelo circulante, pois sem envolver todas as combinações híbridas, as estimativas de CGC teriam magnitudes não comparáveis às obtidas no dialelo completo.

Para avaliar a efetividade ou não desse argumento, foram obtidas as estimativas de CGC nos dois tipos de dialelo e estimada a probabilidade de que os valores obtidos no circulante ocorram dentro do intervalo de confiança da CGC do dialelo completo (Fig. 2). A proporção apresentada em cada situação refere-se às estimativas de CGC no dialelo circulante, para cada um dos pais, que ocorreram no intervalo de confiança da CGC obtida no dialelo completo, para o referido pai. Em princípio, os resultados obtidos são semelhantes aos encontrados em relação às estimativas da correlação de Spearman relatados anteriormente, ou seja, com o aumento no número de pais envolvidos no cruzamento, maior $\mathrm{s}$, a proporção de valores dentro do intervalo de confiança aumenta.

Há, contudo, uma diferença marcante no que se refere à variação com a herdabilidade do caráter. Com o aumento de $\mathrm{h}^{2}$, em geral, a proporção de ocorrência no intervalo diminuiu, para um mesmo s. Isso é facilmente explicado, considerando que, com o aumento de $\mathrm{h}^{2}$, o erro é menor, o intervalo de confiança é mais curto, e reduz a chance de cair no intervalo considerado. Essa variação só não é mais expressiva porque as estimativas de CGC obtidas no dialelo circulante, com maior $\mathrm{h}^{2}$, pela mesma razão já comentada, oscilou menos e aumenta o número de casos que recaem no intervalo considerado. 

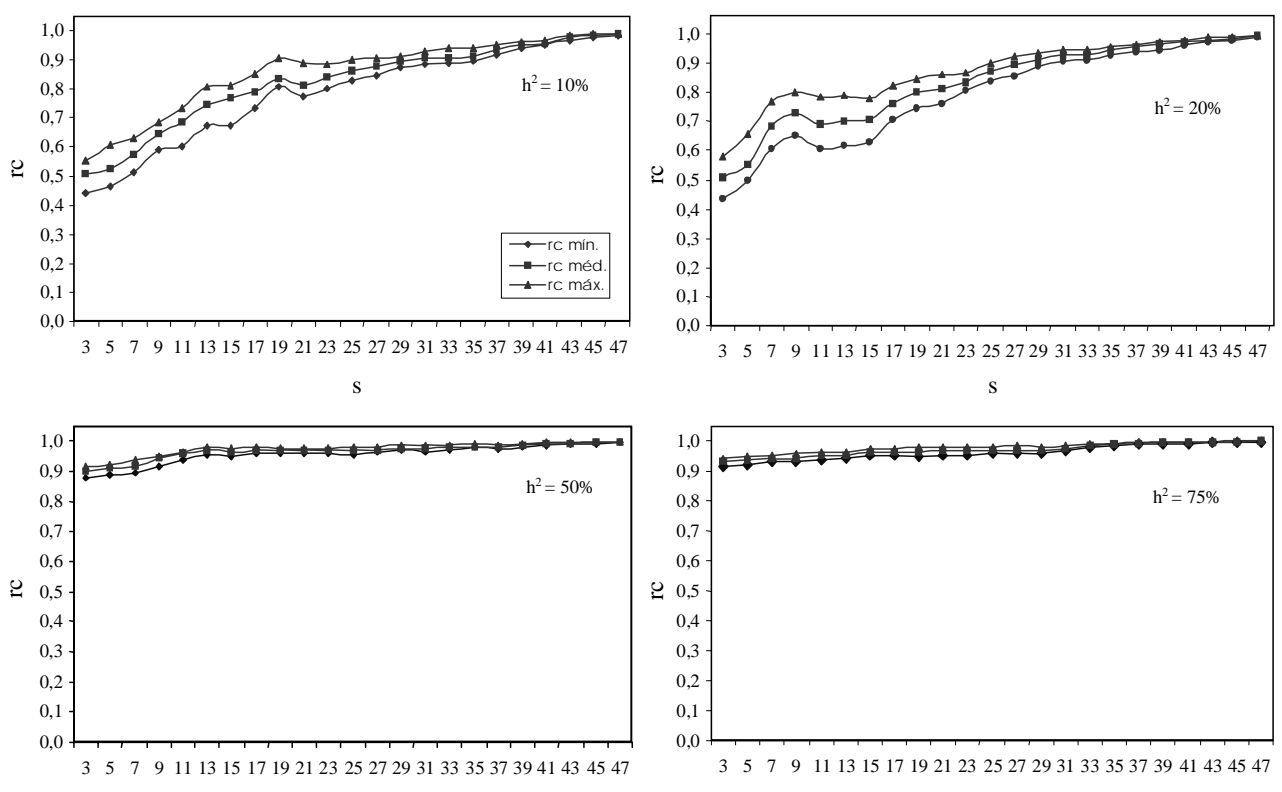

Correlações - CGC - modelos com dominância
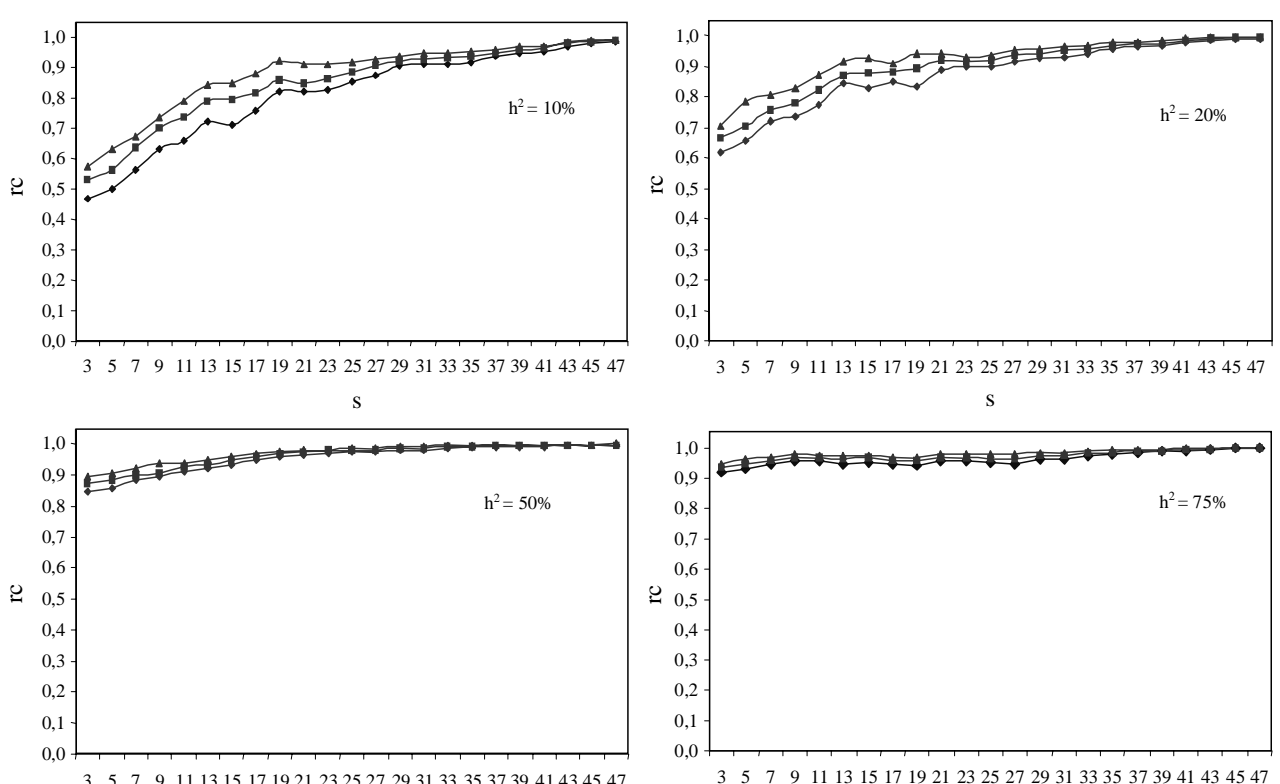

Correlações - CGC - modelos sem dominância

FIG. 1. Estimativas das médias, mínimas e máximas das correlações classificatórias de Spearman (rc) entre as estimativas de capacidade geral de combinação (CGC) no dialelo completo e no circulante, considerando-se diferentes herdabilidades $\left(h^{2}\right)$ e números de cruzamentos de cada pai (s) no circulante, nos modelos com e sem dominância. 

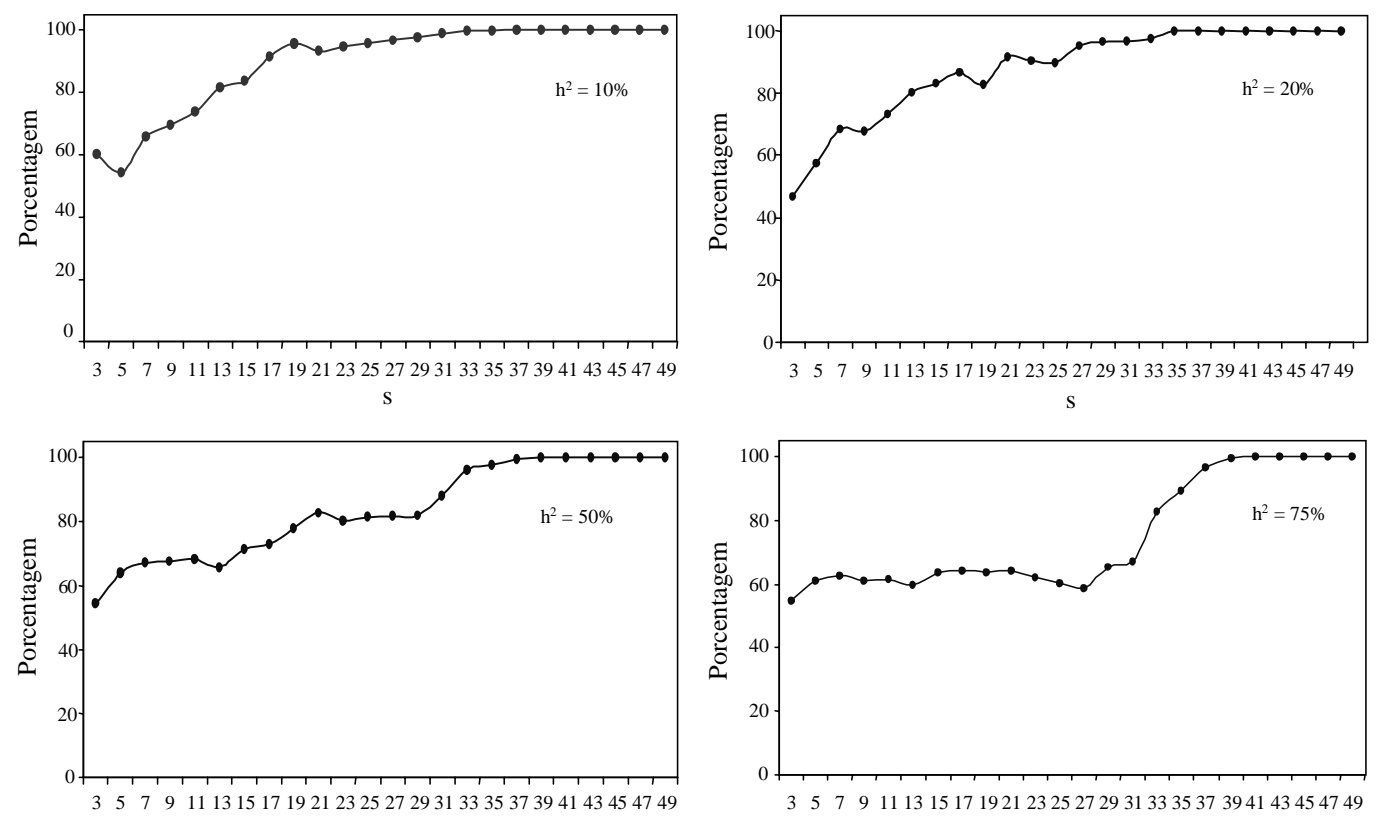

Proporções - CGC - modelos com dominância
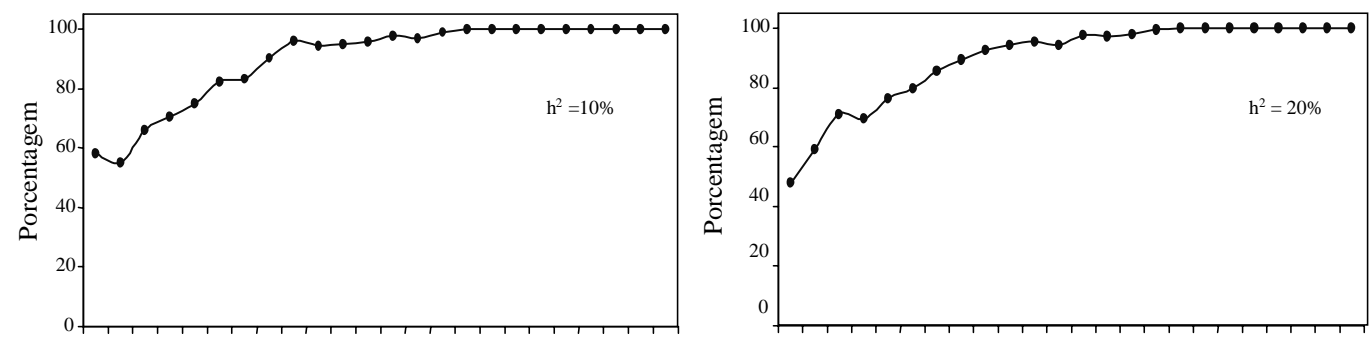

35791113151719212325272931333537394143454749

35791113151719212325272931333537394143454749
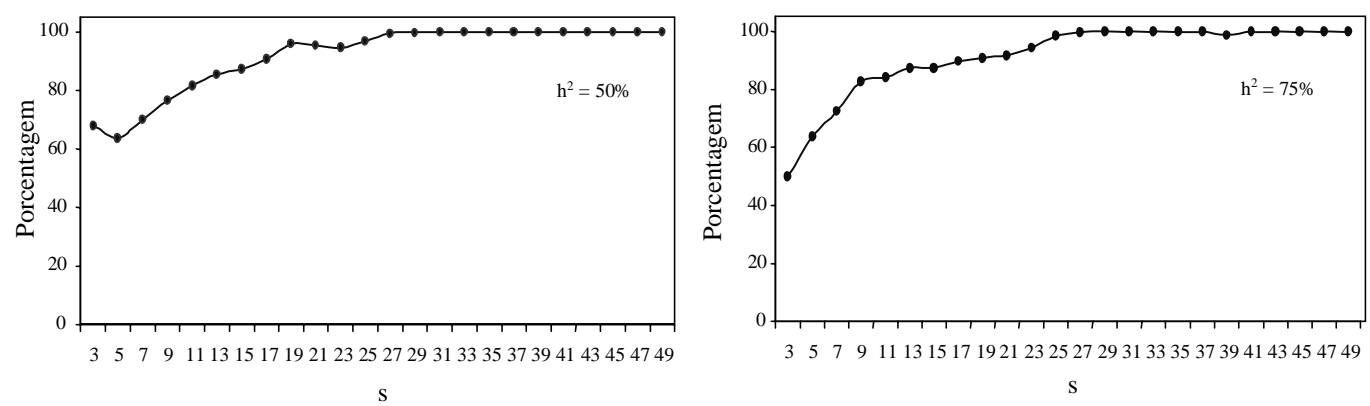

Proporções - CGC - modelos sem dominância

FIG. 2. Proporção das estimativas da capacidade geral de combinação (CGC) obtidas no dialelo circulante, que coincidem com o intervalo de confiança para CGC do dialelo completo, considerando-se 50 simulações para diferentes valores de herdabilidade $\left(h^{2}\right)$ do caráter e números de cruzamentos de cada genitor (s), nos modelos com e sem dominância. 
As proporções obtidas novamente realçam que os dialelos circulantes fornecem praticamente as mesmas estimativas de CGC do dialelo completo, tanto na presença de dominância (Fig. 2), como, e especialmente, na ausência da mesma. Veja que, mesmo com s igual a $3, \mathrm{~h}^{2}$ de $10 \%$, na presença de dominância, $60 \%$ dos valores de CGC do dialelo circulante ocorreram no intervalo de CGC do dialelo completo. Novamente deve ficar evidenciado que, se o melhorista está interessado num ajustamento mais estreito das estimativas, a opção é utilizar maior número de cruzamentos por genitor. Esse número, contudo, seria, no máximo, $50 \%$ do valor de $\mathrm{p}$.

As estimativas da capacidade geral de combinação são úteis para direcionar os futuros trabalhos de hibridação, ou seja genitores com alta CGC devem dar boas combinações híbridas em cruzamentos com os demais genitores (Vencovsky, 1978). Entretanto, quando é realizado o dialelo, o melhorista está interessado em dar continuidade ao seu trabalho, isto é, identificar o par ou pares de combinações híbridas com potencial de permitir identificar linhagens promissoras (Ramalho et al., 1993). Para isso, é necessário obter informações sobre a capacidade específica de combinação (CEC).

Como já salientado, elas só serão diferentes de zero na presença de dominância (Vencovsky, 1978; Falconer, 1981) e quanto maior for a divergência dos dois genitores envolvidos. Assim, uma alta estimativa de CEC, pelo menos em princípio, indica que aquela combinação híbrida possui um maior número de locos em heterozigose, e portanto, a população segregante dela derivada terá maior amplitude de variação (Abreu, 1997), evidentemente ampliando a chance de selecionar linhagens com desempenho superior à dos pais. Do exposto, a estimativa de CEC é de fundamental importância.

No dialelo circulante, analogamente ao dialelo completo, pode-se obter estimativas de CEC dos pares de combinações envolvidas. Novamente foram obtidas por simulação, de maneira semelhante às estimativas de $\mathrm{CGC}$, a correlação classificatória de Spearman (Fig. 3) e a proporção de casos de estimativas de CEC do circulante que ocorreram no intervalo de confiança da mesma CEC no dialelo completo. Observa-se que, no caso das estimativas da correlação de Spearman, os valores foram superio- res aos obtidos para CGC, com relação aos mesmos valores de $\mathrm{s}$. Com s igual a 3 , e mesmo com $\mathrm{h}^{2}$ de $10 \%$, a correlação média foi próxima a 0,8 . Com s igual a 11, os valores da correlação já são superiores a 0,9 e a partir daí, há uma estabilização.

A proporção de ocorrência da estimativa de CEC no dialelo circulante no intervalo de confiança da CEC do dialelo completo também evidencia que o dialelo circulante fornece estimativas de CEC muito similares as do dialelo completo.

O fato mais relevante, contudo, é que no dialelo circulante só é estimada uma pequena proporção das capacidades específicas de combinação possíveis. Novamente, considerando o exemplo com p igual a 50 , no dialelo completo seriam obtidas 1.225 combinações híbridas, e, conseqüentemente, igual número de estimativas da CEC, enquanto no dialelo circulante, com s igual a 3, apenas 75. Isto é, ficariam faltando 1.150 estimativas de CEC.

Como já salientado, essas estimativas de capacidades específicas ausentes são fundamentais ao trabalho dos melhoristas, o que se tornaria uma séria restrição ao emprego desse tipo de dialelo. Essa restrição poderia ser atenuada com algumas alternativas. A primeira delas é que, como já comentado, a CEC é tanto mais expressiva quanto maior a divergência dos pais, assim, os melhoristas poderiam, no momento de realizar os cruzamentos, orientá-los de modo a favorecer as combinações entre genitores mais divergentes. Assim procedendo, só seriam obtidas as combinações que efetivamente são mais promissoras, tornando-se mais uma vantagem a favor dos dialelos circulantes, pois seria obtido e principalmente avaliado um número restrito de combinações. Para identificar os pais mais divergentes, há algumas estratégias, tais como a origem das linhagens, coeficiente de parentesco, o uso de análise multivariada, ou o emprego de marcadores (Baenziger \& Peterson, 1991; Abreu, 1997; Reis, 1998).

A segunda alternativa, para atenuar o limitado número de estimativas de CEC envolvidas no dialelo circulante, é a possibilidade de utilizar procedimentos genético-estatísticos que permitam estimar os valores de CEC em falta. Nesse contexto, algumas opções têm sido apresentadas, como o emprego dos modelos mistos e a predição por meio do BLUP (Bernardo, 1995; Charcosset et al., 1998). 

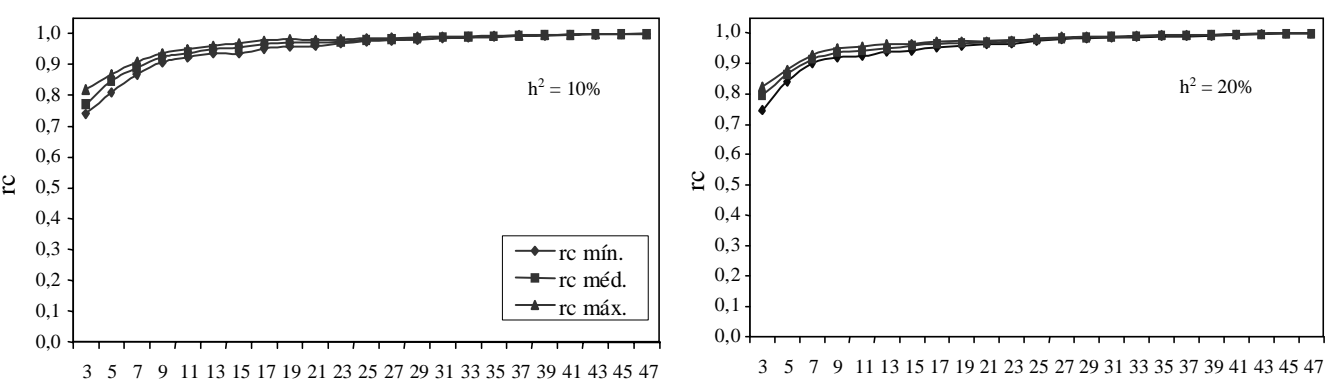

3557911131517192123252729313335373941434547 $\mathrm{s}$
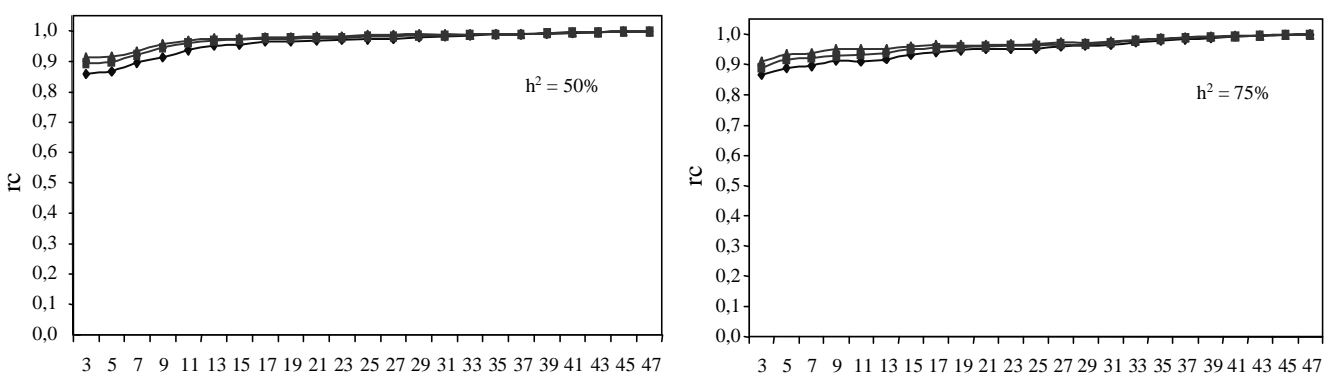

Correlações - CEC
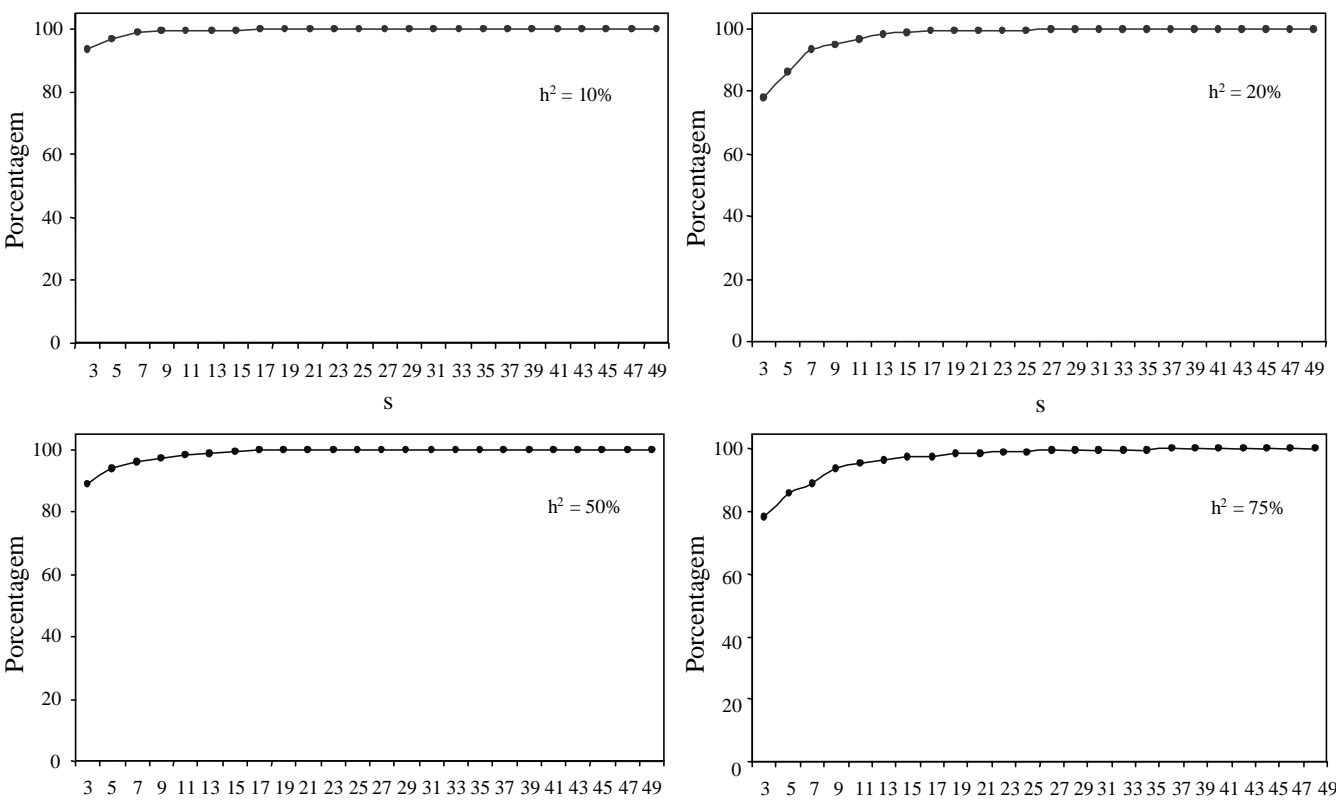

Proporções - CEC

FIG. 3. Estimativas das médias, mínimas e máximas das correlações classificatórias de Spearman e proporções nos intervalos de confiança entre as estimativas de capacidade específica de combinação (CEC) no dialelo completo e no circulante, considerando-se diferentes herdabilidades $\left(h^{2}\right)$ e números de cruzamentos de cada pai (s) no circulante, em modelos com dominância. 
Dialelos de dados experimentais obtidos na literatura

Na literatura, são escassos os dialelos envolvendo um grande número de pais. Na realidade, há na literatura um enorme número de publicações envolvendo cruzamentos dialélicos, em várias espécies, mas, o número de pais em estudo é quase sempre inferior a 15 (Santos, 1984; Otubo, 1994; Gama et al., 1995; Melo, 1996); apenas Naspolini Filho et al. (1981) utilizaram 18 pais e Ferreira (1993) utilizou 28 pais, com a cultura do milho. Essa informação reforça o argumento de que o potencial dos dialelos tem sido pouco explorado pelos melhoristas, por restringir o número de pais envolvidos. Esse fato confirma as observações acima, de que os cruzamentos dialélicos circulantes deveriam ser mais utilizados.

Os resultados das análises de variância obtidos nos experimentos com a cultura do milho por Naspolini Filho et al. (1981) e Ferreira (1993) estão apresentados na Tabela 1. Constatou-se diferença significativa entre os tratamentos em ambos os casos. O mesmo ocorreu quanto à fonte de variação da capacidade geral de combinação. Contudo, no que se refere à capacidade específica de combinação, observou-se diferença significativa apenas na análise realizada com as médias publicadas do experimento com milho obtido com 18 pais.

Vale ressaltar que ocorreu diferença marcante na estimativa de $\mathrm{h}^{2}$ para seleção entre os híbridos. Com as médias advindas do experimento com 28 pais, obteve-se $h^{2}$ igual a $28,2 \%$, enquanto no caso do experimento com 18 pais a estimativa de $\mathrm{h}^{2}$ foi de $63,1 \%$. Depreende-se, então, que no caso de Ferreira (1993) provavelmente ocorreu o mesmo fato comenta- do em relação aos resultados dos dialelos simulados; mesmo tendo dominância, a capacidade específica de combinação só foi detectada com $\mathrm{h}^{2}$ acima de $50 \%$. Esse fato foi, inclusive, salientado por Ferreira (1993), que não detectou efeito significativo no que respeita à fonte de variação $\mathrm{CEC}$, embora a depressão por endogamia dos pais fosse elevada e significativa, indicando a presença de dominância e também de divergência genética. Ressalta-se que, da mesma forma que os experimentos simulados, o experimento de Ferreira (1993) foi conduzido com duas repetições.

Na Fig. 4, são apresentadas as correlações classificatórias de Spearman envolvendo as estimativas de CGC obtidas no dialelo experimental completo e as diferentes simulações dos dialelos circulantes possíveis. Verifica-se que, em média, já no circulante com três cruzamentos por genitor, a correlação foi próxima a 0,6 , no tocante ao dialelo de menor $\mathrm{h}^{2}$ (Ferreira, 1993), e próxima a 0,9 no que diz respeito ao de maior $\mathrm{h}^{2}$ (Naspolini Filho et al., 1981). Observando-se a Fig. 1, que apresenta os dados simulados com $\mathrm{h}^{2}$ igual a $20 \%$, semelhante à obtida por Ferreira (1993), e a com $\mathrm{h}^{2}$ igual a $75 \%$, que é semelhante à obtida por Naspolini Filho et al. (1981), verifica-se que os resultados foram muito coerentes. Assim, com 11 cruzamentos por genitor, com os dialelos circulantes na simulação ( $22 \%$ dos 50 pais), e $\mathrm{h}^{2}$ igual a $20 \%$, a correlação média foi superior a 0,7 .

Com os dados de Ferreira (1993), 22\% de 28 pais correspondem a seis e a correlação média foi também próxima de 0,7 . A mesma observação é válida quando se comparam os resultados de Naspolini Filho et al. (1981) com a h ${ }^{2}$ igual a $75 \%$ no dialelo simulado.

TABELA 1. Resumo das análises de variância dos dialelos e intervalos de confiança (LI e LS) referentes à herdabilidade $\left(\mathrm{h}^{2}\right)$ com $95 \%$ de confiança, considerando os experimentos com dados reais.

\begin{tabular}{|c|c|c|c|c|c|c|c|c|}
\hline \multirow[t]{2}{*}{$\begin{array}{l}\text { Fontes de } \\
\text { variação }\end{array}$} & \multicolumn{4}{|c|}{$\begin{array}{c}\text { Experimento } 1^{1} \\
\text { (Milho - Ferreira, 1993) }\end{array}$} & \multicolumn{4}{|c|}{$\begin{array}{c}\text { Experimento } 2^{2} \\
\text { (Milho - Naspolini Filho et al., 1981) }\end{array}$} \\
\hline & GL & $\mathrm{QM}$ & $\mathrm{F}$ & $\mathrm{P} \%$ & GL & $\mathrm{QM}$ & $\mathrm{F}$ & $\mathrm{P} \%$ \\
\hline Trat. & 405 & 1,8763 & 1,39 & 0,00 & 170 & 2,2711 & 2,71 & 0,04 \\
\hline CGC & 27 & 7,8212 & 5,81 & 0,00 & 17 & 10,4695 & 12,58 & 0,00 \\
\hline CEC & 378 & 1,4517 & 1,08 & 22,96 & 153 & 1,3601 & 1,62 & 0,00 \\
\hline Resíduo & 405 & 1,3471 & & & 1020 & 0,8378 & & \\
\hline
\end{tabular}

${ }^{1}$ Média: 7,25 t/ha; CV: 16,01\%; $\hat{\mathrm{h}}^{2}: 39,28 ; \mathrm{h}^{2}(\mathrm{LI}): 12,74 ; \mathrm{h}^{2}(\mathrm{LS}): 40,93$

${ }^{2}$ Média: 4,27 t/ha; CV: 21,44\%; $\hat{\mathrm{h}}^{2}: 63,11 ; \mathrm{h}^{2}(\mathrm{LI}): 54,00 ; \mathrm{h}^{2}(\mathrm{LS}): 70,97$. 

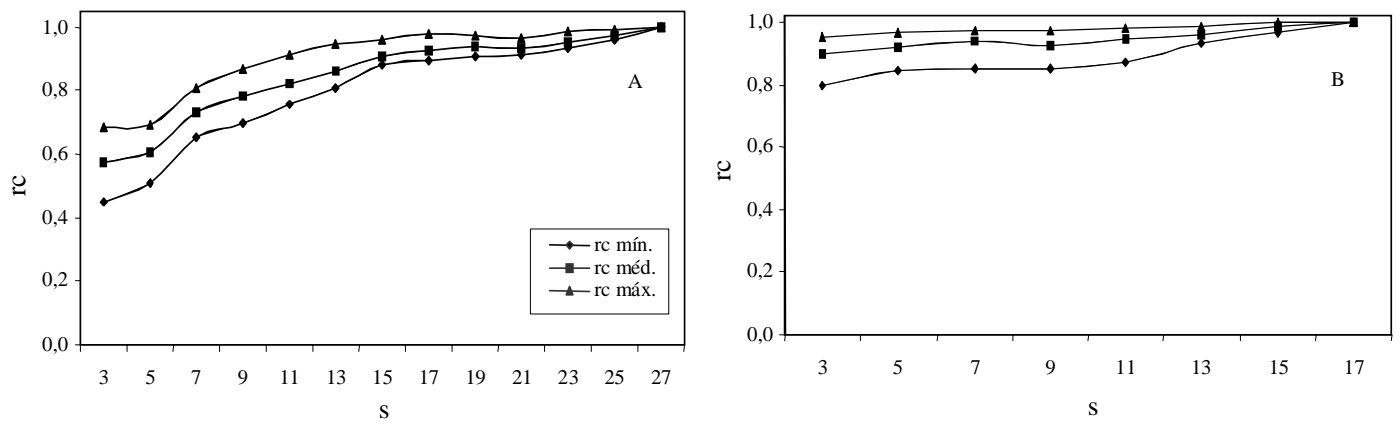

Correlações - CGC
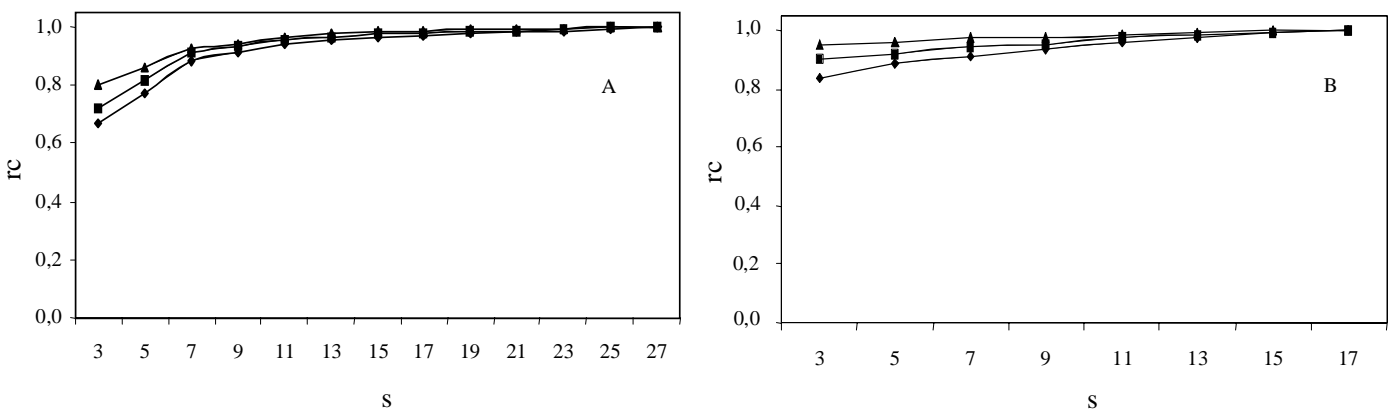

Correlações - CEC
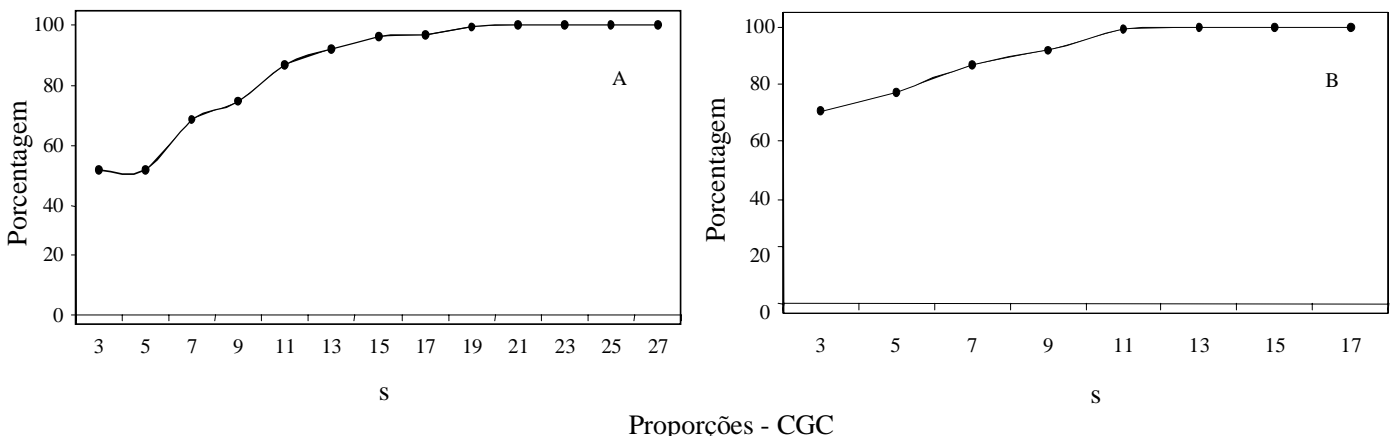

FIG. 4. Estimativas das médias, mínimas e máximas das correlações classificatórias de Spearman entre as estimativas de CGC, de CEC e proporções de estimativas de CGC que coincidem com os intervalos de confiança, no dialelo completo e no circulante, considerando-se experimentos: A - de Ferreira (1993) e B - de Naspolini Filho et al (1981).

As proporções de casos de estimativas de CGC, das 50 simulações do dialelo circulante que ocorreram no intervalo de confiança para as CGC no dialelo completo, estão mostradas na Fig. 2. Verifica-se que, mesmo com três pais envolvidos em cada cruzamento $(\mathrm{s}=3)$, a proporção está em torno de $50 \%$ no experimento com 28 pais, e de $70 \%$ com 18 pais. A partir de $50 \%$ dos pais envolvidos ( $\mathrm{s}=14$ com 28 pais ou 9 com 18 pais), essa proporção já ultrapassa $90 \%$ de coincidência. 
Todos esses resultados mostram que a simulação do dialelo efetuada foi efetiva em refletir uma situação real, o que evidencia a importância dos trabalhos de simulação, em obter informações para os melhoristas, sobretudo porque possibilita envolver situações em que seria praticamente impossível compará-las em condições de campo. Evidenciou-se que os cruzamentos dialélicos circulantes possibilitam aos melhoristas resultados bem semelhantes aos que seriam obtidos com os dialelos completos. Esse fato, como já evidenciado, reduz consideravelmente o número de cruzamentos a serem obtidos e avaliados, possibilitando que, na escolha dos pais ou das populações segregantes, seja possível explorar com maior intensidade o germoplasma disponível.

Ficou evidenciado que o valor de s depende da herdabilidade para a seleção de híbridos, podendo ser tanto menor quanto maior for $\mathrm{a} \mathrm{h}^{2}$. Contudo, mesmo com $\mathrm{h}^{2}$ baixa, ele não necessita ultrapassar a $50 \%$ do número total de genitores, conforme foi acima descrito. Ao que parece, os estudos com o objetivo de avaliar a eficiência de circulantes não haviam abrangido até então o número necessário de pais e não haviam atingido a amplitude que os recursos de simulação possibilitaram no presente trabalho.

Um argumento que poderia ser aventado é o de que os melhoristas não possuem condições a priori de saber qual $\mathrm{h}^{2}$ será obtida para a seleção dos híbridos no dialelo, ficando difícil, assim, ter informações sobre a magnitude do valor de $\mathrm{s}$. Um bom critério seria utilizar as estimativas do coeficiente de variação $(\mathrm{CV})$ referente à característica de interesse, o qual é comumente obtido nas condições experimentais em que os híbridos serão avaliados. Se as estimativas do CV são normalmente de magnitude média ou alta, indicando baixa precisão, é um indício de que a $\mathrm{h}^{2}$ a ser obtida será pequena e, nessa condição, o número de cruzamentos por pai deverá ser maior. Em caso de boa precisão, a $\mathrm{h}^{2}$ deverá ser alta, e o s poderá ser pequeno.

No dialelo circulante, o número de cruzamentos a serem avaliados é muito inferior ao dos dialelos completos, e há possibilidade de que os experimentos sejam conduzidos com maior número de repetições. Esse procedimento, como já mostrado, aumenta a chance de se detectar significância quanto à capacidade específica, quando existe dominância, aliada à presença de divergência entre os pais.

\section{CONCLUSÕES}

1. Os dialelos circulantes demonstram eficiência comparável à dos completos, tanto na classificação dos pais quanto à capacidade geral e à capacidade específica de combinação, como na magnitude das estimativas desses parâmetros.

2. No dialelo circulante, o número de cruzamentos de cada pai (s) afeta as estimativas de capacidade geral e específica de combinação, mas mesmo com um pequeno valor de $\mathrm{s}$ é possível obter uma boa concordância nas estimativas em relação aos dialelos completos.

3. Especialmente em condições de baixa herdabilidade, é vantajoso aumentar o número de cruzamentos de cada pai; a melhoria na eficiência ocorre com o aumento de s até o máximo da metade do número de pais envolvidos, com o que já se consegue alta eficiência dos dialelos circulantes em todos os casos

\section{REFERÊNCIAS}

ABREU, A.F.B. Predição do potencial genético de populações segregantes do feijoeiro utilizando genitores inter-raciais. Lavras : UFLA, 1997. 79p. Tese de Doutorado.

BAENZIGER, P.S.; PETERSON, E.J. Genetic variation: its origin and use for breeding self-pollinated species. In: STALKER, H.T.; MULTRIPHY, J.P. (Ed.). Plant breeding in the 1990's. Raleigh : North Caroline State University, 1991. p.69-100.

BERNARDO, R. Genetic models for predicting maize single-cross performance in unbalanced yield trial data. Crop Science, Madison, v.35, p.141-147, 1995.

CHARCOSSET, A.; BONISSEAU, B.; TOUCHEBEUF, O.; BURSTIN, J.; DUBREUIL, P.; BARRIËRE, Y.; GALLAIS, A.; DENIS, J.B. Prediction of maize hybrid silage performance using marker data: comparison of several models for specific combining ability. Crop Science, Madison, v.38, p.38-44, 1998.

CRUZ, C.D.; REGAZZI, A.J. Modelos biométricos aplicados ao melhoramento genético. Viçosa : UFVImprensa Universitária, 1994. 390p.

FALCONER, D.S. Introdução à genética quantitativa. Viçosa : UFV-Imprensa Universitária, 1981. 279p.

Pesq. agropec. bras., Brasília, v.35, n.7, p.1395-1406, jul. 2000 
FERREIRA, D.F. Métodos de avaliação da divergência em milho e suas relações com os cruzamentos dialélicos. Lavras : UFLA, 1993. 72p. Dissertação de Mestrado.

GAMA, E.E.G. e; HALLAUER, A.R.; LOPES, M.A.; PARENTONI, S.N.; SANTOS, M.X.; GUIMARÃES, P.E.O. Combining ability among fifteen early cycle maize populations in Brazil. Brazilian Journal of Genetics, Ribeirão Preto, v.18, n.4, p.569-577, 1995.

GRIFFING, B. Concept of general and specific combining ability in relation to diallel crossing systems Australian Journal of Biological Sciences, Collingwood, v.9, p.463-493, 1956.

KEMPTHORNE, O.; CURNOW, R.N. The partial diallel cross. Biometrics, Alexandria, v.17, p.229-250, 1961

KNAPP, S.J.; STROUP, W.W.; ROSS, W.M. Exact confidence intervals for heritability on a progeny mean basis. Crop Science, Madison, v.25, n. 1, p.192194, Jan./Feb. 1985

MELO, L.C. Escolha de genitores visando à obtenção de cultivares de feijoeiro tolerantes à baixa temperatura na fase adulta. Lavras : UFLA, 1996. 80p. Dissertação de Mestrado.

MURTY, B.R.; ANAND, I.J. Combining ability and diversity in some varieties of Linus uritatissemum. Indian Journal of Genetics and Plant Breeding Calcutta, v.26, p.21-36, 1966.

MURTY, B.R.; ARUNACHALAM, V.; ANAND, I.J Diallel and partial diallel analysis of some yield factors in Linus uritatissemum. Heredity, Oxford, v.22, p.35-41, 1967.

NASPOLINI FILHO, V.; GAMA, E.E.G. e; VIANNA, R.T.; MÔRO, J.R. General and specific combining ability for yield in a diallel cross among 18 maize populations (Zea mays L.). Brazilian Journal of Genetic, Ribeirão Preto, v.4, n.4, p.571-577, 1981

OTUBO, S.T. Controle genético da tolerância do feijoeiro (Phaseolus vulgaris $L$.) a baixas temperaturas na fase de germinação. Lavras : UFLA, 1994. 50p. Dissertação de Mestrado.

RAMALHO, M.A.P.; SANTOS, J.B. dos; ZIMMERMANN, M.J.O. Genética quantitativa em plantas autógamas: aplicações ao feijoeiro. Goiânia : UFG, 1993. 271p

REIS, W.P. Divergência genética entre cultivares brasileiros de trigo recomendados no Brasil. Piracicaba : ESALQ, 1998. 77p. Tese de Doutorado.

SANTOS, J.B. dos. Controle genético de caracteres agronômicos e potencialidades de cultivares de feijão (Phaseolus vulgaris L.) para o melhoramento genético. Piracicaba : ESALQ, 1984. 223p. Tese de Doutorado.

SAS INSTITUTE (Cary, Estados Unidos). SAS language and procedures: usage. Cary, 1995. 373p

SNEDECOR, G.W.; COCHRAN, W. Statistical methods 7.ed. Ames : The Iowa State College Press, 1982. $507 \mathrm{p}$

SOUZA, E.A. Alternativas experimentais na avaliação de progênies em programas de melhoramento genético vegetal. Piracicaba : ESALQ, 1997. 122p. Tese de Doutorado.

VEIGA, R.D. Eficiência dos dialelos circulantes na escolha de genitores, avaliada com simulação de dados. Lavras : UFLA, 1998. 95p. Tese de Doutorado

VENCOVSKY, R. Herança quantitativa. In PATERNIANI, E. (Ed.). Melhoramento e produção do milho no Brasil. Campinas : Fundação Cargill, 1978. p.122-201. 